\section{NICE TRANSPARENCY}

\section{Let cost effectiveness models be open to scrutiny}

In light of the recent ruling over the National Institute for Health and Clinical Excellence's (NICE) decision on donezepil, ${ }^{2}{ }^{2}$ we wish to comment on the adversarial system of drug evaluation and the inadequacy of NICE providing read only versions of cost effectiveness models for the purposes of reviewing their decisions.

The assertion that "NICE is not in a position to deal with the reality of restrictions being placed on the models by those who supply them" ${ }^{2}$ is not defensible. NICE could specify terms and conditions to technology assessment groups (TAGs) to allow full disclosure of what, after all, is publicly funded research. Indeed, they should be disclosed under the Freedom of Information Act, with non-disclosure acceptable only when in the public interest.

Recently, the Sheffield TAG published a correction to a cost effectiveness model for multiple sclerosis treatment caused by a coding error. ${ }^{3}$ This model underpinned a high profile and novel shared risk policy. ${ }^{4}$ Because even the simplest deterministic models need thousands of calculations, usually coded by one person, errors are hardly surprising. More sophisticated simulation models use complex computational routines, the detail of which is rarely scrutinised. Under current TAG contracts NICE cannot quality assure these models. Furthermore, a recent objective comparison of validated health economic models for diabetes found wide variability. ${ }^{5}$

The current adversarial system of economic evaluation is unacceptable to all stakeholders. Cost effectiveness models could be produced by consensus under the joint direction of NICE and industry. This would reduce costs and hasten access to health technologies that all agree are good value for money.

Chris Poole director, Pharmatelligence LLP, Cardiff MediCentre, Cardiff drchrispoole@googlemail.com Samir Agrawal consultant haematologist, Department of Haematological Oncology, St Bartholomew's Hospital, London Craig J Currie honorary senior research fellow, Department of Medicine, Cardiff University, Cardiff

Competing interests: CJC and CP have worked for several drug companies in the preparation of NICE submissions. SA has represented the Royal College of Pathologists in a previous NICE appeal. Pharmatelligence is a health outcomes consultancy, mainly to the drug industry; it has received neither instruction nor payment from the industry about this letter.

1 Chalmers I. The Alzheimer's Society, drug manufacturers, and public trust. BMJ 2007;335:400. (25 August.)

2 England and Wales High Court (Administrative Court) Decisions. Between Eisai Limited (claimant) and the National Institute for Health and Clinical Excellence (defendant). 2007. www.bailii.org/ew/cases/EWHC/ Admin/2007/1941.html.

3 Modelling the cost effectiveness of interferon $\beta$ and glatiramer acetate in the management of multiple sclerosis. Correction for Chilcott et al BMJ 2003;326:522. BMJ 2007;334. (24 March.) doi: 10.1136/ bmj.39155.488704.BE.

4 Sudlow CL, Counsell CE. Problems with UK government's risk sharing scheme for assessing drugs for multiple sclerosis. BMJ 2003;326:388-92.

5 The Mount Hood 4 Modeling Group. Computer modeling of diabetes and its complications. A report on the Fourth Mount Hood Challenge Meeting. Diab Care 2007;30:1638-46.

\section{THE PRIMARY CARE MARKET}

\section{More questions than answers}

Pollock et al ask "how will National Health Service spending be accounted for in the new primary care market?"

When I asked to see the financial details of the contracts with private providers the reply was, "I can confirm that the department holds details of the cost of the Walk in Centre and general medical services, however it is not currently prepared to release this information."

With all the talk of competition, some questions remain. Why are personal medical services, alternative medical provider services, and private contractors not offered the same capitations as general medical service contractors, determined by an allocation formula that takes account of patients' needs? ${ }^{2}$ Why did the advisory board for alternative medical provider contracts contain several of the private companies that are now providing primary care services? ${ }^{3}$

A final detail, the Barking and Dagenham surgery and walk-in centre (that reputedly received $£ 5 \mathrm{~m}(€ 7 \mathrm{~m} ; \$ 10 \mathrm{~m})$ for a five year contract) is not catering for 7000 patients yet-that is the number of patients who will potentially be registered at the end of the five year period. ${ }^{4}$ How many patients are registered for primary care services and at what cost is known by the Department of Health only for the time being.
Hendrik J Beerstecher general practitioner principal, Sittingbourne, Kent ME10 4JA

hendrick.beerstecher@nhs.net

Competing interests: None declared.

1 PollockAM, Price D, ViebrockE, Miller E, Watt G. The market in primary care. BMJ 2007;335:475-7. (8 September.)

2 Morgan CL, Beerstecher HJ. Primary care funding, contract status, and outcomes. An observational study. BrJ Gen Pract 2006;56:825-9.

3 The NHS confederation. APMS core group meeting. 21 July 2004, London. www.bmj.com/cgi/content/ full/335/7622/DC1.

4 Day M. UK government accused of privatising the NHS. BM/ 2006;333:61. doi: 10.1136/bmj.333.7558.61.

\section{ALCOHOL INDUSTRY}

\section{Brazil's market is unregulated}

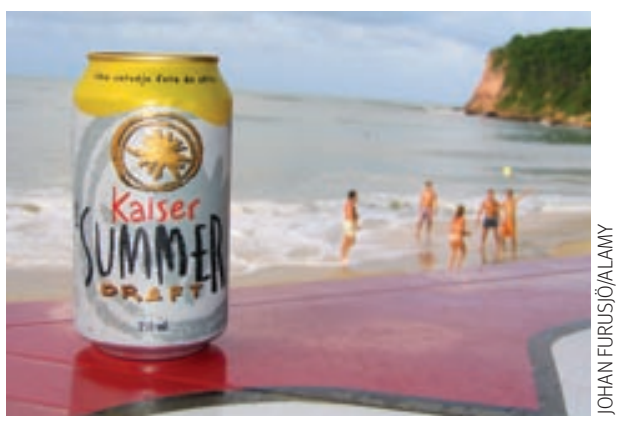

Farrell warns of the health implications of the unwelcome partnership between the alcohol industry and the health sector. ${ }^{1}$ Brazil has one million selling points for alcohol in a population of 180 million. These points can sell alcohol at any time of day, to anybody, including minors. We have a very aggressive advertising strategy on television that reaches millions of children. In recent research on a random sample of drivers, $30 \%$ of them had alcohol in their blood. Brazil is by any account an unregulated market for alcohol, and the alcohol industry is trying to keep it that way. This lack of regulation contributes to the $10 \%$ increase in consumption each year.

If that were not enough, the alcohol industry has approached health professionals to advocate a harm reduction approach as the best policy for tackling this problem in Brazil.

Ronaldo R Laranjeira senior lecturer on addictive behaviour, Federal University of São Paulo, São Paulo 04023-000, Brazi laranjeira@uniad.org.br

Competing interests: None declared.

1 Farrell M. The alcohol industry: taking on the public health critics. BMJ 2007;335:671. (29 September.) 


\section{DECLARATION OF HELSINKI}

\section{Dead}

Servicing the overarching interests of the drug and medical device industry, the United States has apparently successfully intervened in the past (and still tries) with provisions that weaken the protection of human subjects, taking the document farther and farther from the principles and intent of the Nuremberg Code. The World Medical Association, it appears, has been party to medical malpractice in its most wanton manifestation. Fortunately, unlike the Nuremberg Code, most courts of law do not rely on the Declaration of Helsinki for guidance.

The answer to Goodyear et al's question"Declaring Helsinki-alive or dead?"-seems to be that the Declaration of Helsinki is dead on the basis of no brain waves, no heart beat, and a rapidly bloating, blow fly infested, stinking cadaver. ${ }^{1}$

Cynically, one must ask "what is the purpose of current efforts to "harmonise" the ethics and legalities of clinical trials in countries with no device regulatory system?" How can one "harmonise" the practice of numerous unethical experiments conducted by researchers with no "internalised ethical values?" How can one "harmonise" wholesale failure to internalise ethical values?" As the ethicist Arthur Caplan said, "In many ways, rats and mice get greater protection as research subjects in the United States than do humans." ${ }^{2}$

Efforts to change the Declaration of Helsinki that come from the US should be recognised for what they represent. The United States and the US Federal Drug Administration have abdicated oversight of human subjects research, as indicated by a recent report of the US Department of Health and Human Services inspector general, “. . . f federal health officials did not know how many clinical trials were being conducted, audited fewer than $1 \%$ of the testing sites and, on the rare occasions when inspectors did appear, generally showed up long after the tests had been completed." 2

Perhaps it is time to turn to the Canadian Ottawa Statement, to which the authors approvingly refer.

John H Noble Jr retired, Georgetown, TX 78633, USA jhnoble@verizon.net

Competing interests: JHN read and commented on the authors' original draft

1 Goodyear MDE, Krleza-Jeric K, Lemmens T. The Declaration of Helsinki. BMJ 2007;335:624-5. (29 September.)

2 Harris G. Report assails FDA oversight of clinical trials. New York Times 28 Sept 2007.
CAM

\section{What to do about CAM?}

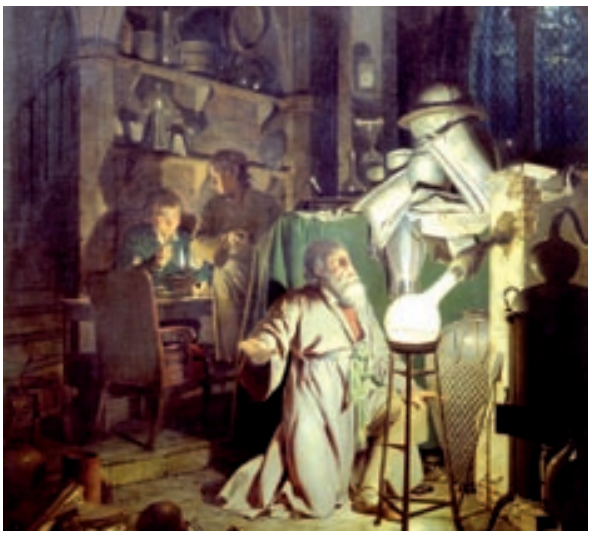

Joseph Wright of Derby: the alchemist

Doug Kamerow seems excessively tolerant of people who make lots of money out of unproved and disproved treatments. ${ }^{1}$

I prefer the straight talking of his compatriot, Gerald Weissmann, "If the trend persists, perhaps MIT (Massachusetts Institute of Technology) or Cal Tech will march in step with the medical schools and offer prizes for integrative alchemy or alternative engineering." ${ }^{2}$ Or Wallace Sampson, "It is time for Congress to defund the National Center for Complementary and Alternative Medicine (NCCAM). After ten years of existence and over $\$ 200$ million in expenditures, it has not proved effectiveness for any 'alternative' method. It has added evidence of ineffectiveness of some methods that we knew did not work before NCCAM was formed."3

That is something that could be done-the expenditure on NCCAM is now close to $\$ 1 \mathrm{bn}(£ 0.5 \mathrm{bn} ; € 0.7 \mathrm{bn})$.

In the UK National Health Service, primary care trusts are, quite rightly, withdrawing funding from homoeopathy. Tunbridge Wells Homeopathic Hospital will close and the Royal London Homeopathic Hospital is in great danger. ${ }^{4}$ Something has been done, at last.

David Colquhoun professor of pharmacology, University College London, London WC1E 6BT

d.colquhoun@ucl.ac.uk

Competing interests: None declared.

1 Kamerow D. Wham, bam, thank you CAM. BMJ 2007;335:647. (29 September.)

2 Weissmann G. Homeopathy: Holmes, Hogwarts, and the Prince of Wales. FASEB / 2006;20:1755-8.

3 Sampson WI. Why the National Center for Complementary and Alternative Medicine (NCCAM) should be defunded. www.quackwatch.org/ 01QuackeryRelatedTopics/nccam.html.

4 DC's improbable science. Tunbridge Wells Homeopathic Hospital to close. 2007. http://dcscience.net/?p=167

5 DC's improbable science. The Royal London Homeopathic Hospital (RLHH) has problems. 2007. www.dcscience.net/improbable.html\#rlhh3.

\section{MORE GOING APE}

\section{Psychosocial interventions?}

Given that the serotonin theory of depression has been dismissed as a myth propagated by the drug industry, ${ }^{1}$ and given the efficacy of psychosocial interventions, I was surprised that Pop considered only a pharmacological approach when treating a depressed gorilla. $^{2}$

While even the most enthusiastic evangelists of cognitive behaviour therapy might acknowledge the limitations of cognitive restructuring in a gorilla, more pragmatic activity scheduling and behavioural activation both have a good evidence base as stand alone treatments for depression.

Damasio conceptualised emotional experience as being embedded within visceral and musculoskeletal states. ${ }^{3}$ In depression, reduced efferent activity from the peripheral nervous system can be stimulated by dance movement therapy, another proved treatment for depression.

Ayurvedic philosophy, and more recently Harrison et al, ${ }^{5}$ have shown an association between low mood and overcrowding. This could be the case at the zoo, and a letter in support of rehousing, the ubiquitous default intervention of the helpless psychiatrist, might have been useful.

Dian Fossey observed the importance of social hierarchy in gorilla groups, and Pop's patient's withdrawal from the role of alpha male may have precipitated an existential crisis characterised by a failure to negotiate Erikson's final task of development-integrity versus despair. Or in the words of The Jungle Book's King Louie, "I'm (was) the king of the swingers, the jungle VIP. I've got to the top and then had to stop and that's what's bothering me."

Dave W H Baillie specialist registrar in adult psychiatry, East London and the City Mental Health NHS Trust, London N16 OLN Dave.Baillie@elcmht.nhs.uk

Competing interests: None declared.

1 Lacasse JR, Leo J. Serotonin and depression: a disconnect between the advertisements and the scientific literature. PloS Med 2005;2:e392

2 Pop IC. A depressed gorilla. BMJ 2007;335:445. doi: 10.1136/bmj.39245.483900.AD.

3 Damasio A. Descartes error: emotion, reason and the human brain. London: Vintage Books, 1994.

4 Jeong YJ, Hong SC, Lee MS, Park MC, Kim YK, Suh CM. Dance movement therapy improves emotional responses and modulates neurohormones in adolescents with mild depression. Int J Neurosci 2005;115:1711-20.

5 Harrison J, Barrow S, Creed F. Social deprivation and psychiatric admission rates for different diagnostic groups. BrJ Psychiatry 1995;167:456-62. 